\title{
"THE FAUNA OF STONEFLIES (INSECTA: PLECOPTERA) IN UZBEKISTAN “
}

\author{
Lebedeva N.I., Akhmedova Z.Y., Mustafaeva Z.A., Kholmatov B.R., Mirzaeva G.S. \\ Institute of Zoology of the Academy of Sciences of Uzbekistan, Tashkent, Uzbekistan. \\ E-mail: n_lebedeva60@mail.ru E-mail: z_akhmedova@mail.ru E-mail: zuri05@mail.ru
}

\begin{abstract}
:
The article highlights information on the study of the fauna of stoneflies existing in the watercourses of Uzbekistan. Substantiating original collections and data from literary sources, a revision of the fauna of stoneflies in Uzbekistan, which includes 48 species from 19 genera and 7 families, was conducted. The endemic species have been identified for Central Asia and Uzbekistan for the first time.
\end{abstract}

Key words:

Plecoptera, stoneflies, revision, fauna, family, genus, species, endemic.

Article Received: 18 October 2020, Revised: 3 November 2020, Accepted: 24 December 2020

\section{INTRODUCTION}

In spite of the fact that multilateral studies were conducted on the biodiversity of Uzbekistan's ecosystems, in particular water, the available information is scarce and insufficient to solve the environmental problems of our time and, therefore, additional scientific work is required in this field. The lack of information on hydrobionts (aquatic organisms), which are the important components of indicators of the ecological state, is especially acute, and in this term, water quality of surface sources is considered to be stoneflies of the Plecoptera detachment.

The purpose of this work was to revise and study the modern species composition of the fauna of stoneflies of watercourses in Uzbekistan.

\section{MATERIAL AND METHODS}

From May to November 2017-2019, the monitor on the sites of stonefly breeding, exposed to varying degrees of anthropogenic impact, was conducted. Moreover, the route surveys of flowing freshwater reservoirs of various types (rivers, rivulets, springs, irrigation collectors and ditches), together with the visual inspection of stones and submerged vegetation in water were carried out in 5 regions of Uzbekistan: northeastern (Tashkent city, Tashkent region), eastern (Namangan, Fergana regions), central
(Bukhara, Jizzakh, Navoi, Samarkand regions), southern (Kashkadarya, Surkhandarya regions) and southwestern (Republic of Karakalpakstan) [Mustafaeva et al., 2017].

During visual inspection of stones and submerged vegetation near the coast and on rifts, the collection of larvae/nymphs of stoneflies from water bodies was carried out manually or with tweezers, as well as a sample of macrozoobenthos was subtracted from the water body. In order to conduct this process, depending on the depth and flow rate of the watercourse, stones and other flooded objects were washed into a hydrobiological net $(\varnothing 20 \mathrm{~cm}$, weaved from the gauze fabric). Or collectors dug up pebbles and stones with their feet in front of a net placed against the stream so that insects would fall into the net [Teslenko and Zhiltsova, 2009].

The biomass collected in a net was carefully washed under running water, then transferred to a container with tweezers, fixing with a $70^{\circ}$ ethanol solution and providing a label indicating the date and place of collection, coordinates, and the name of the collector. The larvae/nymphs of stoneflies collected by visual inspection of stones and flooded objects were selected manually or with tweezers, immediately placed in a separate container and fixed with a $70^{\circ}$ ethanol solution, which was labeled with the 
date and place of collection, coordinates, and the name of the collector. Later, in the laboratory of Entomology of the Institute of Zoology of the Academy of Sciences of the Republic of Uzbekistan, they analyzed the washings of macrozoobenthos according to systematic groups to levels of type, class or order according to F. Mayer's method, conducting qualitative and quantitative accounting of the collected biomass [GOST 17.1.3.07-82; Recommendations of RUz 52.25.32-97]. Microscopic examination of insects was carried out using MEIJITECHNO stereoscopic and biological microscopes.

The collection of adults of stoneflies found on plants, stones, or other objects near water bodies and near the water surface was carried out manually or with tweezers. Flying insects were caught with an entomological net by the "mowing" method over vegetation (100 strokes of $1 \mathrm{~m}$ in one direction and back). Then the collected insects were placed in a separate container, fixed with a $70^{\circ}$ solution of ethanol, or, having killed, on a cotton mattress. Samples were labeled accordingly, indicating the date and place of collection, coordinates, and the name of the collector.

The identification of stoneflies was carried out mainly according to the larval stages of development (2,493 larvae/nymphs, 375 adults) using the corresponding identification tables [Teslenko and Zhiltsova, 2009].

The collected material is kept in the funds of the Entomological Collection of the Institute of
Zoology of the Academy of Sciences of the Republic of Uzbekistan.

\section{RESEARCH RESULTS}

The monitoring of the breeding sites of stoneflies was carried out in the watercourses of 5 regions of Uzbekistan (northeastern, eastern, central, southern and southwestern) and made it possible to obtain data on their uneven, sometimes even, local settlement. The survey covered 129 watercourses in 32 regions of the republic (Tashkent city, 9 regions and the Republic of Karakalpakstan) and 663 samples of macrozoobenthos were collected.

The index of occurrence of stoneflies in the republic in samples of zoobenthos was $37.1 \%$, in regions - $28.1 \%$. Most often, stoneflies were found in the mountain-foothill watercourses of the northeastern and southern (33.3\%), central $(22.2 \%)$ and eastern $(11.1 \%)$ regions. Stoneflies were not found in samples from the southwestern region (steppe, desert) of the republic (Republic of Karakalpakstan).

On the basis of original collections of larvae/nymphs of stoneflies in the watercourses of the republic and adults around them, as well as data from literary sources, we revised the fauna of stoneflies in Uzbekistan, taking into account synonymous names, which made it possible to clarify the composition of the fauna of stoneflies in Uzbekistan (table). 


\begin{tabular}{|c|c|c|}
\hline Family & Genus & Species \\
\hline \multicolumn{3}{|c|}{ Group Systellognatha Enderlein, 1969 : Zwick, 2000} \\
\hline \multirow[t]{13}{*}{$\begin{array}{l}\text { Perlodidae Klapálek, } \\
1912\end{array}$} & Isoperla Banks, 1906 & $\begin{array}{l}\text { Isoperla difformis Klapálek, } 1909 \\
\text { (=Chloroperla difformis Klapálek, } \\
\text { 1909) }\end{array}$ \\
\hline & & Isoperla sp. \\
\hline & $\begin{array}{l}\text { Mesoperlina } \\
\text { Klapálek, } 1921\end{array}$ & $\begin{array}{lrr}\text { Mesoperlina capnoptera } & \text { (McLachlan, } \\
\text { 1886) (=Chloroperla } & \text { capnoptera } \\
\text { McLachlan, } 1886 & - & \text { fam. } \\
\text { Chloroperlidae)* } & & \end{array}$ \\
\hline & & Mesoperlina ochracea Klapálek, 1921 \\
\hline & & Mesoperlina pecirkai Klapálek, 1921* \\
\hline & & Mesoperlina sp. \\
\hline & $\begin{array}{l}\text { Arcynopteryx } \\
\text { Klapálek, } 1904\end{array}$ & $\begin{array}{l}\text { Arcynopteryx compacta McLachlan, } \\
1892\end{array}$ \\
\hline & Diura Billberg, 1820 & Diura knowltoni Frison, $1937 * *, * * *$ \\
\hline & & Diura sp. \\
\hline & $\begin{array}{l}\text { Filchneria Klapálek, } \\
1908\end{array}$ & $\begin{array}{lll}\text { Filchneria } & \text { mesasiatica } & \text { Zhiltzova, } \\
1971^{*}, * * * & & \end{array}$ \\
\hline & & Filchneria mongolica (Klapálek, 1901) \\
\hline & & $\begin{array}{l}\text { Filchneria olgae McLachlan, } 1875 \\
\text { (=Dictyopteryx olgae McLachlan, } \\
1875 ; \text { Skobeleva olgae (McLachlan, } \\
1875)^{*}\end{array}$ \\
\hline & & Filchneria sp. \\
\hline \multirow[t]{5}{*}{ Perlidae Latreille, 1802} & $\begin{array}{lr}\text { Agnetina } & \text { Klapálek, } \\
1907 \quad(=P e r l a \\
\text { Geoffroy, 1761) }\end{array}$ & $\begin{array}{l}\text { Agnetina cocandica (McLachlan, 1875) } \\
\text { (=Kamimuria costulata Navás, } \underline{1923} ; \text {; } \\
\text { Perla cocandica McLachlan, 1875; } \\
\text { Phasganophora undata Klapálek, } \\
\text { 1921) }\end{array}$ \\
\hline & & $\begin{array}{l}\text { Agnetina immersa (McLachlan, 1875) } \\
\text { (=Perla immersa } \text { McLachlan, 1875)* }\end{array}$ \\
\hline & & $\begin{array}{l}\text { Agnetina pedata (Koponen, 1949) } \\
\text { (=Phasganophora pedata Koponen, } \\
\text { 1949)* }\end{array}$ \\
\hline & & Agnetina sp. (=Phasganophora sp.). \\
\hline & $\begin{array}{l}\text { Dinocras } \quad \text { Klapálek, } \\
1907 \quad \text { : } \\
1940\end{array}$ & $\begin{array}{l}\text { Dinocras cephalotes (Curtis, 1827) } \\
\text { (=Perla baetica Rambur, 1842; Perla } \\
\text { cephalotes Curtis, 1827) }\end{array}$ \\
\hline Chloroperlidae Okamoto, & Chloroperla & Chloroperla tripunctata (Scopoli, \\
\hline
\end{tabular}

\section{Species composition of stoneflies (Plecoptera) of watercourses in Uzbekistan}

Note: * - endemics of the mountains of Central Asia and Kazakhstan, ** - identified for the first time for Central Asia, *** - identified for the first time for Uzbekistan.
It can be seen from the data in the table that the fauna of stoneflies (Plecoptera) in Uzbekistan includes 48 species from 19 genera and 7 families, of which 2 species are established to subspecies and 9 to genus.

The Systellognatha group is represented by 22 species from 10 genera and 3 families: 
Perlodidae - 13 species from 5 genera, Perlidae - 5 species from 2 genera and Chloroperlidae - 4 species from 3 genera. Of these, 7 species are endemics of the mountains of Central Asia and Kazakhstan, 1 species was identified for the first time for Central Asia and 2 species were identified for the first time for Uzbekistan.

More than half of the fauna of the Systellognatha group consists of species of the Perlodidae family (13 species or $59.1 \%$ ) belonging to 5 genera: Mesoperlina and Filchneria - 4 species each, Diura and Isoperla - 2 species each, Arcynopteryx - 1 species, then species of the Perlidae family (5 species or $22.7 \%$ ) belonging to 2 genera: Agnetina - 4 species, Dinocras - 1 species and the family Chloroperlidae (4 species or 18.2\%) - 3 genera: Xanthoperla - 2 species, Chloroperla and Siphonoperla - 1 species each.

Among modern collections, the following are widespread and numerous: Mesoperlina pecirkai (Klapálek, 1921) in northeastern, eastern, and southern regions and Diura knowltoni (Frison, 1937) in northeastern, central, and southern regions, less widely species are Xanthoperla curta (McLachlan, 1875) in north -east and central regions) and locally: Mesoperlina ochracea (Klapálek, 1921) in the eastern region, Filchneria mesasiatica (Zhiltzova, 1971) and Agnetina immersa (McLachlan, 1875) in the northeastern region.

The Eucholognatha group is represented by 26 species from 9 genera of 4 families: Taeniopterygidae - 1 species from 1 genus, Nemouridae - 15 species from 4 genera, Capniidae - 9 species from 3 genera, Leuctridae 1 species from 1 genus. Of these, 11 species are endemics of the mountains of Central Asia and Kazakhstan, 3 species have been identified for the first time in Uzbekistan.

More than half of the fauna of the Eucholognatha group consists of species of the Nemouridae family (15 species or $57.7 \%)$ belonging to 4 genera: Amphinemura - 8 species, Nemoura and Mesonemoura - 3 species each and
Illiesonemoura - 1 species, then species of the Capniidae family ( 9 species or $34,6 \%$ ), belonging to 3 genera: Capnia and Eucapnosis - 4 species each and Mesocapnia - 1 species and then 2 families (1 species each or $3.8 \%)$ : Taeniopterugidae: genus Mesyatsia - 1 species and Leuctridae: genus Leuctra - 1 species.

Of the modern collections, they are widespread and numerous: Amphinemura trialetica Zhiltzova, 1957, Mesonemoura tianshanica (Zhiltzova, 1971) and Mesonemoura vaillanti (Navás, 1922) (northeastern, eastern and southern regions) and locally: Amphinemura mirabilis turkestanica Zhiltzova, 1978 (southern region) and Mesocapnia altaica (ZapekinaDulkeit, 1955) (northeastern region).

\section{CONCLUSION}

The monitor of stoneflies was carried out in 129 watercourses of 5 regions (32 districts) of the republic: northeastern (Tashkent city, Tashkent region), eastern (Namangan, Fergana regions), central (Bukhara, Jizzakh, Navoi, Samarkand regions), southern (Kashkadarya, Surkhandarya regions) and southwestern (Republic of Karakalpakstan), made it possible to obtain data on their uneven, sometimes even, local settlement.

The index of occurrence of stoneflies in the republic in samples of zoobenthos was $37.1 \%$, in regions $-28.1 \%$. Most often, stoneflies were found in the mountain-foothill watercourses of the northeastern and southern (33.3\%), central $(22.2 \%)$ and eastern $(11.1 \%)$ regions. Stoneflies were not found in samples from the southwestern region (steppe, desert) of the republic (Republic of Karakalpakstan).

After revising the literature data and own collections, the fauna of stoneflies (Plecoptera) in Uzbekistan includes 48 species from 19 genera and 7 families, of which 2 species were established to subspecies and 9 species to genus; 18 species of stoneflies are endemics of the mountains of Central Asia and Kazakhstan, 1 species was first identified for the fauna of Central Asia (Diura knowltoni (Frison, 1937)) and 5 
species - for Uzbekistan (Diura knowltoni (Frison, 1937); Filchneria mesasiatica (Zhiltzova, 1971); Amphinemura trialetica (Zhiltzova, 1957); Mesonemoura vaillanti (Navás, 1922); Mesocapnia altaica (Zapekina-Dulkeit, 1955)). Species superiority (54.2\% of the total number of species) is shifted towards the group of phyto- and detritivores - Eucholognatha, instead of $45.8 \%$ of the group of predators - Systellognatha.

The revealed species composition of the detachment of Plecoptera of Uzbekistan cannot yet be considered complete. This can be judged by comparing the species composition of the Plecoptera fauna of the countries of Central Asia adjacent to Uzbekistan (Kyrgyzstan, Tajikistan, Turkmenistan and Kazakhstan). It can be assumed that further research (new foothill-mountain streams, collections in the autumn-winter and early spring periods, molecular genetic studies) will be able not only to clarify the species composition, but to replenish the list of species given in this work and expand the understanding of the biological features of stoneflies in the foothill-mountain streams of Uzbekistan.

\section{FUNDING}

This work was carried out with the financial support of the grant of the Academy of Sciences of the Republic of Uzbekistan No. VA-FA-F5-011 "Orthopteroid insects (Insecta: Orthopteroidea) of Uzbekistan" (2017-2020).

\section{REFERENCES}

[1] Mustafaeva Z.A., Mirzaev U.T. and Kamilov B.G., 2017. Methods of hydrobiological monitoring of water bodies in Uzbekistan. Toolkit. Tashkent. Navruz. $102 \mathrm{p}$.

[2] Recommendations: RUz 52.25.32-97, 1997. Methods of hydrobiological monitoring of water bodies in the Central Asia region. Tashkent. $67 \mathrm{p}$.

[3] State Standard (GOST) 17.1.3.07-82 Nature Protection. Hydrosphere. Rules for monitoring the quality of water, reservoirs and streams.

[4] Teslenko V.A. and Zhiltsova L.A., 2009. Key to stoneflies (Insecta, Plecoptera) of Russia and neighboring countries. Imago and larvae. Vladivostok: Dalnauka, Rossian academy of sciences. 382 p. http://padaread.com/data/djvu/1c/ef/204333/ Opredelitel-vesnyanok-Insecta-PlecopteraRossii-i-sopredelnyh-stran/1.png. 